\title{
Nickel Nanopillar Arrays Electrodeposited on Silicon Substrates Using Porous Alumina Templates
}

\author{
Matías Bejide ${ }^{1,2}{ }^{\mathbb{D}}$, Patricio Contreras ${ }^{3}$, Pia Homm ${ }^{1}$, Boris Duran ${ }^{2}$, \\ José Antonio García-Merino ${ }^{1,2}{ }^{-}$, Andreas Rosenkranz ${ }^{1,2}$, Juliano C. Denardin 4 , \\ Rodrigo del Río ${ }^{2,3}$ and Samuel A. Hevia ${ }^{1,2, *}$ \\ 1 Instituto de Física, Pontificia Universidad Católica de Chile, Casilla 306, Santiago 6904411, Chile; \\ mabejide@uc.cl (M.B.); phomm@uc.cl (P.H.); jose.garcia@uc.cl (J.A.G.-M.); anrosenkranz@uc.cl (A.R.) \\ 2 Centro de Investigación en Nanotecnología y Materiales Avanzados, Pontificia Universidad Católica de \\ Chile, Casilla 306, Santiago 6904411, Chile; bgduran@uc.cl (B.D.); rdelrioq@uc.cl (R.d.R.) \\ 3 Facultad de Química, Pontificia Universidad Católica de Chile, Casilla 306, Santiago 6904411, Chile; \\ contreras@uc.cl \\ 4 Department of Physics, University of Santiago and CEDENNA, Santiago 9170124, Chile; \\ juliano.casagrande@usach.cl \\ * Correspondence: samuel.hevia@fis.uc.cl; Tel.: +56-9-9998-6438
}

Academic Editors: Mikhail N. Khrizanforov and Giuseppe Cirillo

Received: 1 October 2020; Accepted: 11 November 2020; Published: 17 November 2020

\begin{abstract}
Nickel nanopillar arrays were electrodeposited onto silicon substrates using porous alumina membranes as a template. The characterization of the samples was done by scanning electron microscopy, X-ray diffraction, and alternating force gradient magnetometry. Ni nanostructures were directly grown on $\mathrm{Si}$ by galvanostatic and potentiostatic electrodeposition techniques in three remarkable charge transfer configurations. Differences in the growth mechanisms of the nanopillars were observed, depending on the deposition method. A high correlation between the height of the nanopillars and the charge synthesis was observed irrespective of the electrochemical technique. The magnetization measurements demonstrated a main dependence with the height of the nanopillars. The synthesis of $\mathrm{Ni}$ nanosystems with a controllable aspect ratio provides an effective way to produce well-ordered networks for wide scientific applications.
\end{abstract}

Keywords: nanomaterial; anodic aluminum oxide; well-ordered nanopores; electrochemical routes

\section{Introduction}

Complex nanostructures with well-organized matrix distribution and multi-modal physical behaviors are potential candidates for implementation in nanotechnology [1]. Specifically, nanowires (NWs) and nanopillars (NPillars) of Ni have many potential applications in a broad spectrum of areas, including data storage, magneto-electronics, quantum magneto-optics, biomedical science, spintronics, electrolysis, and lithium battery electrodes [2-8]. These technologies have a common interest in developing devices at low cost and with high throughput to produce diverse nanosystems [9]. In this context, electrochemical methods can be considered potential candidates for Npillars and NWs fabrication since they can be synthesized with various aspect ratios [10]. These structures were reported to enhance the magnetic properties with respect to $\mathrm{Ni}$ thin films because they present two principal axes of polarization [11]. In particular, Ni-NW and Ni-Npillars can be grown using well-distributed pores of anodic aluminum oxide (AAO) templates [12,13]. Generally speaking, Ni-NWs directly attached to semiconductors typically need several steps to be produced [14]. However, potentiostatic and galvanostatic electrochemical techniques can greatly simplify and increase the synthesis efficiency of Ni nanostructures [15]. 
Potentiostatic and galvanostatic electrochemical fabrication methods produce Ni-Npillars with magnetic properties due to the creation of polycrystalline grains with different shapes [16]. For example, Ni-NWs with diameters of $30 \mathrm{~nm}$ and $60 \mathrm{~nm}$ and a height of $10 \mu \mathrm{m}$ have been electrodeposited on AAO templates using a potentiostatic procedure with AC and DC. The magnetic characteristics in the long axis of the wires, such as coercivity $\left(\| H_{c}\right)$, increased with decreasing diameter [17]. Similar results are reported for the galvanostatic electrodeposition of Ni-NWs of $20 \mathrm{~nm}$ and $200 \mathrm{~nm}$ diameter and $60 \mu \mathrm{m}$ height [18]. However, in these samples, the perpendicular saturation field $\left(\perp H_{s}\right)$ is smaller for the potentiostatic electrodeposited Ni-NWs compared to their galvanostatic counterpart [13]. Additionally, the magnetic properties of Ni-Npillars and NWs have an attractive implication due to the symmetrical angular propagation of electromagnetic waves [19]. This behavior has been well reported for Ni-NWs and can be explained by the strong correlation between the magnetic characteristics and shape anisotropy [20]. The effect of the morphology on the magnetic hysteresis loops is strongly pronounced for magnetically soft particles, such as $\mathrm{Ni}$ [21]. In addition, the preparation of Ni-Npillars with controlled dimensions covering areas on the order of $\mathrm{cm}^{2}$ attached to a semiconductor surface becomes an attractive topic in applied science [22]. For instance, Ni-Npillars have been used to develop potential lithium-ion battery electrodes $[8,23]$. Sn nanospheres were directly grown on Ni-Npillars to improve the volume charge in a lithium-ion battery anode; this alloy stabilizes the structure and suppresses the expansion during the reaction [24].

In this manuscript, a study of electrodeposited ordered arrays of Ni-Npillars on Si substrates using a porous alumina membrane (PAM) as a template is presented. The Ni-Npillars were directly grown onto the substrate, which is highly relevant from the scientific and technical points of view since it allows us to obtain cylindrical nanostructures with scalable ratios and immediate applications. The Ni-Npillars were fabricated by galvanostatic and potentiostatic electrochemical techniques and exhibited different growth mechanisms and magnetic properties, which depended on the respective fabrication method.

\section{Results}

Figure 1 shows scanning electron microscopy (SEM) micrographs of the sample synthesized by galvanostatic electrodeposition at $1 \mathrm{C}$ charge. Figure 1a shows a top view image of the PAM after $\mathrm{Ni}$ electrodeposition. A well-defined hexagonal pattern generated by the anodization process can be observed. Moreover, Figure $1 \mathrm{~b}$ shows a top view of the Ni-Npillars after removing the PAM. The nanostructures follow the hexagonal arrangement of the template and show a quasi-circular cross-section with a mean diameter of $58.4 \pm 8.8 \mathrm{~nm}$ and an interpore distance of $95.8 \pm 7.2 \mathrm{~nm}$, estimated based upon histograms of the AAO pattern distribution, as in Figure 1a. Initially, the Ni-Npillars tend to grow mainly parallel to each other, as observed in Zone 1 marked in Figure $1 \mathrm{~b}$. However, when their aspect ratio exceeds a critical value, the pillars tend to form bundles, as shown in Zone 2 of Figure 1b. Figure 1c shows a side view SEM micrograph of the Ni-Npillars after the template removal. As expected, the Ni-Npillars have grown perpendicular to the Si substrate with a rather broad height distribution. Only one sample was chosen to represent the morphological characteristics since similar trends were observed for all other samples, irrespective of the deposition technique and adjusted charge. 


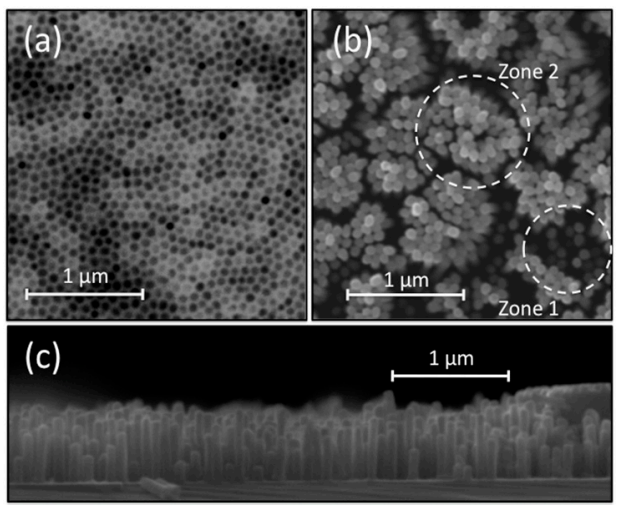

Figure 1. SEM micrographs. (a) Top view of the porous alumina membrane with Ni-Npillars electrodeposited inside the pores. (b) Top view and (c) side view of Ni-Npillars on Si substrate after removing the PAM template.

Figure 2 summarizes the histograms of the height distribution of all Ni-Npillars samples as a function of the electrical charge and the electrodeposition method. This information has been obtained from a set of cross-section SEM micrographs, as shown in Figure 1c. The samples fabricated by the potentiostatic process (Figure 2a,c,e) demonstrate a rather broad height distribution, with the presence of a double peak for the two first synthesis charges. For the array with a synthesis charge of $2 \mathrm{C}$ (Figure 2c), a much less pronounced double peak structure is seen, with one peak being much pronounced, having a mean height of $666 \mathrm{~nm}$. In the case of the array with a synthesis charge of $3 \mathrm{C}$, a wider single peak distribution can be seen, with an average height of $844 \mathrm{~nm}$ (Figure 2e). For samples fabricated with the galvanostatic method, a synthesis charge of $1-3 \mathrm{C}$ (Figure $2 \mathrm{~b}, \mathrm{~d}, \mathrm{f})$, generally narrower single-peak distributions with mean values of $477 \mathrm{~nm}, 828 \mathrm{~nm}$, and $1157 \mathrm{~nm}$ respectively, can be observed. For the galvanostatic depositions, the Ni-Npillars distribution tends to be wider, with an increase in the height mean value. In contrast, the potentiostatic technique generates high current densities with a high growth rate at the beginning of the process, leading to a large number of crystal nuclei [25].

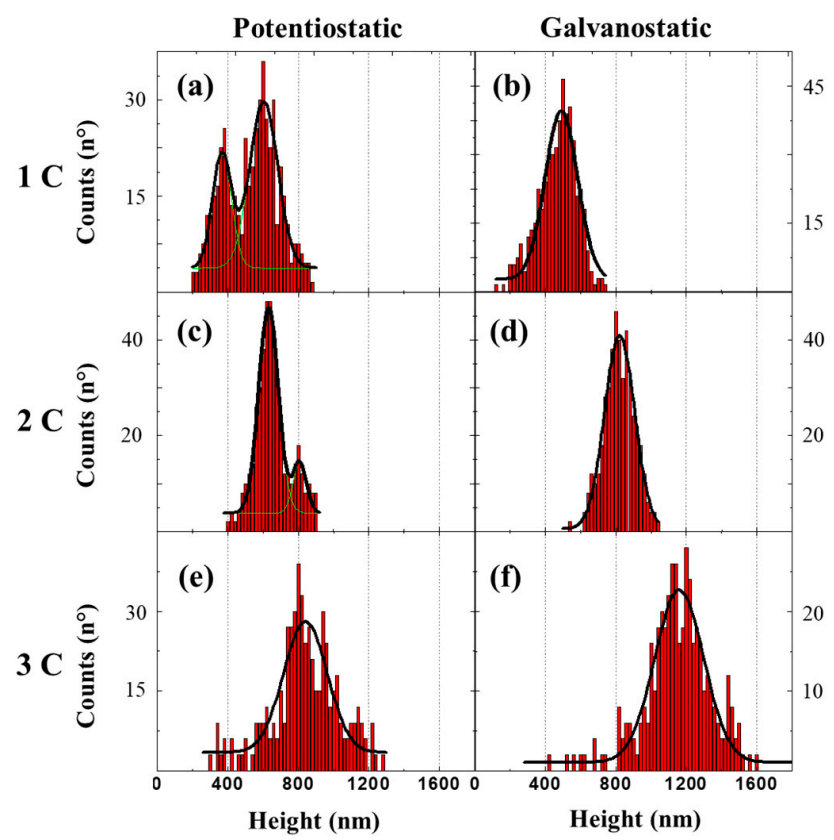

Figure 2. Histogram plots of the respective height distribution of all Ni-Npillars samples for both fabrication techniques as a function of the electrical charge. Potentiostatic at: (a) $1 \mathrm{C},(\mathbf{c}) 2 \mathrm{C}$, and (e) $3 \mathrm{C}$. Galvanostatic at: (b) 1 C, (d) 2 C, and (f) 3 C. 
Figure 3 depicts the resulting XRD measured by grazing incidence for all fabricated samples. At first glance, similar diffraction peaks can be found irrespective of the fabrication technique and electrical charge. Samples fabricated at $3 \mathrm{C}$ of synthesis electrical charge, regardless of the used technique, demonstrate small differences in their spectra, which can be traced back to the formation of $\mathrm{NiO}$ during air exposure $[26,27]$. To analyze the crystallographic nature of the Ni nanostructures, the spectra of Figure 3 was deconvoluted. The double peaks observed near $38^{\circ}$ and $65^{\circ}$ correspond to a mixture of the same diffraction maxima, generated by two slightly different $\mathrm{X}$-ray frequencies, $\mathrm{CuK} \alpha$ and $\mathrm{CuK} \beta$. Moreover, the band close to $45^{\circ}$ has two contributions, which can be attributed to Ni and $\mathrm{NiO}$, thus resulting in a broader and asymmetric peak. For further analysis, all double and asymmetric peaks were deconvoluted, and only the bands belonging to $\mathrm{CuK} \alpha$ radiation were selected. The exposed spectra exhibit five distinguished peaks: two for $\mathrm{Ni}\left(45.2^{\circ}\right.$ and $\left.52.3^{\circ}\right)$ and three for $\mathrm{NiO}\left(38.4^{\circ}, 44.8^{\circ}\right.$, and $\left.64.8^{\circ}\right)$. Similar values were reported elsewhere [28-30]. The respective maximum positions indicate the type of unit cell and lattice parameters for $\mathrm{Ni}$ and $\mathrm{NiO}$. The unit cell of both materials was determined to be face-centered cubic (fcc) and polycrystalline, with an interatomic distance of $3.53 \AA$ for $\mathrm{Ni}$ and $4.67 \AA$ for $\mathrm{NiO}$, calculated using Bragg's law [31]. Moreover, by computing the full width at half maximum (FWHM), average values of $1.15 \mathrm{rad}$ for potentiostatic and $1.07 \mathrm{rad}$ for galvanostatic samples were estimated. Furthermore, using the Debye-Scherer equation [32], the calculated grain sizes of the Ni-Npillar arrays were $8.3 \mathrm{~nm}$ and $9.6 \mathrm{~nm}$ for the potentiostatic and the galvanostatic routes, respectively.
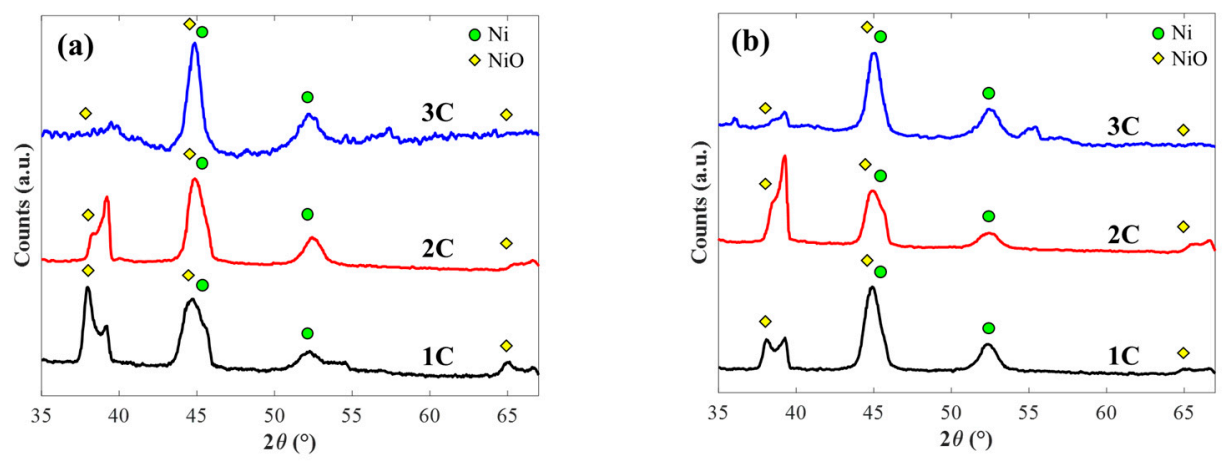

Figure 3. XRD measurements by grazing incidence for all samples as a function of the electrical charge for (a) potentiostatic and (b) galvanostatic electrodeposition.

Figure 4 shows a set of hysteresis curves measured for two different directions of the external magnetic field with respect to the long axis of the Npillars. The inset in Figure 4a shows the parallel (II) and perpendicular $(\perp)$ room temperature magnetization isotherms. Based upon these curves, a change of the magnetic behavior can be observed depending on the fabrication technique and parameters. It is observed that the easy axis is perpendicular to the Ni-Npillars orientation for the $1 \mathrm{C}$ potentiostatic sample and parallel to the pillars axis for the $2 \mathrm{C}$ and $3 \mathrm{C}$ samples. Moreover, there is no preferent magnetization to the wire axis for the $1 \mathrm{C}$ and $2 \mathrm{C}$ galvanostatic samples, but an easy axis parallel to the pillar axis is revealed for the $3 \mathrm{C}$ galvanostatic sample. For both fabrication techniques, the saturating field decreases in the parallel direction as the synthesis charge increases from $1 \mathrm{C}$ to $3 \mathrm{C}$. In general, for both axes, an increase in the charge promotes a bigger coercivity. In the same direction, from Figure 2 it is observed that the mean heights $(L)$ of the Ni-Npillars increase with the charge level. This implies that the magnetic response can be tuned with the morphological aspect ratio of the nanostructures [33]. To study the interdependency between the parameters, such as the coercivity field $\left(H_{c}\right)$, saturation field $\left(H_{s}\right)$, remanence $\left(M_{\mathrm{r}}\right)$, and the mean heights $(L)$ of the Ni-Npillars, the correlations between these variables have been estimated. The respective summary is given in Table 1. 
Potentiostatic
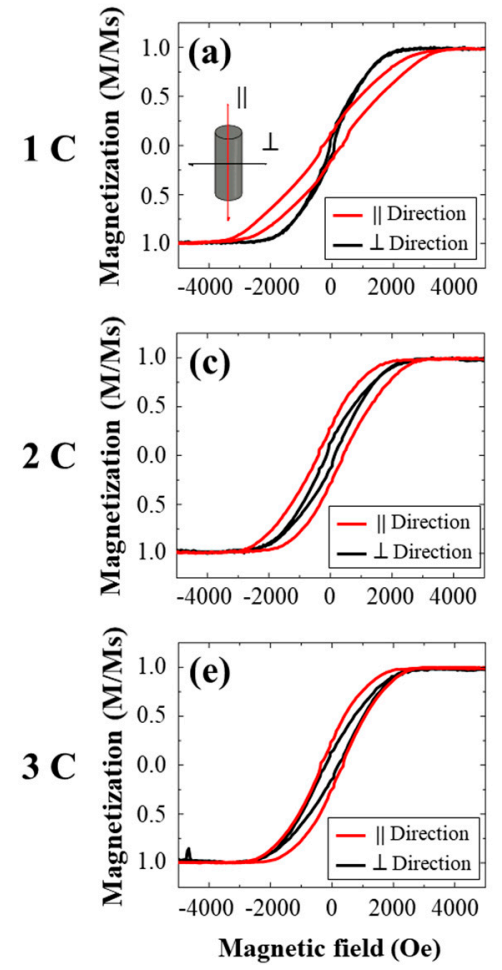

Galvanostatic
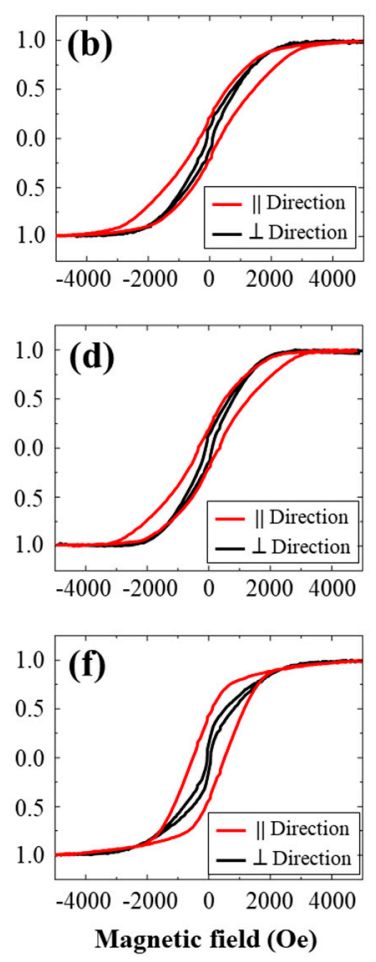

Figure 4. Hysteresis curves of the deposited Ni-Npillars with a parallel alignment external magnetic field (red) and perpendicular alignment (black). Potentiostatic at: (a) 1 C, (c) 2 C, and (e) 3 C. Galvanostatic at: (b) 1 C, (d) 2 C, and (f) 3 C.

Table 1. Parallel and perpendicular magnetic properties of Ni-Npillars and their correlation variables. The blanks are either one between the same variable, or the same value with respect to its symmetry.

\begin{tabular}{|c|c|c|c|c|c|c|c|c|c|c|c|c|}
\hline \multirow{2}{*}{ Method } & \multicolumn{3}{|c|}{ Potentiostat } & \multicolumn{3}{|c|}{ Galvanostat } & \multicolumn{6}{|c|}{ Correlation } \\
\hline & $1 \mathrm{C}$ & $2 \mathrm{C}$ & $3 \mathrm{C}$ & $1 \mathrm{C}$ & $2 \mathrm{C}$ & $3 \mathrm{C}$ & $L$ & $\| H_{c}$ & $\perp \boldsymbol{H}_{c}$ & $\| M_{\mathrm{r}}$ & $\perp M_{\mathbf{r}}$ & $\| H_{s}$ \\
\hline$L(\mathrm{~nm})$ & 486 & 655 & 818 & 481 & 812 & 1130 & - & - & - & - & - & - \\
\hline$\| H_{c}(\mathrm{Oe})$ & 633 & 814 & 741 & 703 & 690 & 1036 & 0.81 & - & - & - & - & - \\
\hline$\perp H_{c}(\mathrm{Oe})$ & 133 & 263 & 427 & 187 & 212 & 288 & 0.5 & 0.39 & - & - & - & - \\
\hline$\| M_{\mathrm{r}}(\mathrm{M} / \mathrm{Ms})$ & 0.13 & 0.28 & 0.25 & 0.21 & 0.18 & 0.43 & 0.81 & 0.99 & 0.48 & - & - & - \\
\hline$\perp M_{\mathrm{r}}(\mathrm{M} / \mathrm{Ms})$ & 0.11 & 0.13 & 0.14 & 0.12 & 0.13 & 0.15 & 0.92 & 0.79 & 0.75 & 0.83 & - & - \\
\hline$\| H_{S}(\mathrm{Oe})$ & 3641 & 3000 & 2738 & 3391 & 3296 & 2440 & -0.87 & -0.87 & -0.79 & -0.91 & -0.94 & - \\
\hline$\perp H_{S}(\mathrm{Oe})$ & 2380 & 2293 & 2738 & 2811 & 2640 & 2851 & 0.49 & 0.37 & 0.34 & 0.41 & 0.49 & -0.45 \\
\hline
\end{tabular}

Based on Table 1, it is possible to observe that parallel magnetic properties are strongly related. These relations may be attributed to the well-correlated height of the Npillars. It is essential to distinguish that $\| H_{s}$ has a good correlation with all variables (negative absolute value), in contrast to $\perp H_{S}$, which cannot be related to other properties since every pillar is above a critical length $\left(L_{c}\right)$. It is expected for $\perp H_{s}$ to be affected if the Npillars are below $L_{c}$ due to an in-plane magnetic anisotropy. This value can be estimated as $L_{c}=1.27 D^{3} / d^{2}$, where $D$ is the interpore distance and $d$ is the diameter pore [34]. The critical value from the average parameters of this work was computed at $283.2 \mathrm{~nm}$, which is less than every Npillar height. Moreover, there is no good correlation between the height of the Npillars and $\perp H_{c}$ [35]. Nevertheless, these Npillars are polycrystalline and do not show an extraordinary preferential magnetic orientation [36].

Furthermore, since the height of the Ni-Npillars determines almost every magnetic parameter, similar loop behaviors can be expected for both directions for the $1 \mathrm{C}$ potentiostatic and $1 \mathrm{C}$ galvanostatic, as well as for the $3 C$ potentiostatic and $2 C$ galvanostatic samples. From Figure $4 a, b$, a similar loop for the parallel direction can be observed. However, the potentiostatic array shows a smaller saturation 
field in the perpendicular direction. Figure $4 \mathrm{~d}$,e present different behaviors, despite their similar average height. Moreover, the potentiostatic samples exhibit a more sensitive dependence in the perpendicular direction and a monotonic increase in the $\| H_{c}$, with respect to the synthesis charge. This can be attributed to different behaviors induced by distinct polycrystalline grain growth in the Ni-Npillars, depending on the deposition method. This phenomenon can explain the observed discrepancies. For instance, if the potentiostatic samples grow with more elongated grains in the perpendicular direction, the $\perp H_{c}$ is expected to increase due to more overlapping grains or increased heights [22]. Additionally, the easy axis orientation perpendicular to the applied field for the $1 \mathrm{C}$ sample could be explained with ellipsoid-like grains, which exhibit anisotropy in their long axis [33,36,37]. In contrast, the galvanostatic samples with $1 \mathrm{C}$ and $2 \mathrm{C}$ are more isotropic, while the sample with $3 \mathrm{C}$ presents the highest Npillars, thus implying the greatest anisotropy. The effect in the $3 \mathrm{C}$ sample can be mainly attributed to the large height that makes it easy to magnetize in the wire axis. Moreover, the rather similar behavior observed in Figure $4 b$,d, although showing a height difference of $331 \mathrm{~nm}$ between the individual nanostructures, can be associated with a more spherical grain shape distribution for the galvanostatic sample [33]. In this context, it is also important to point out that potentiostatic and galvanostatic methods tend to generate different crystalline phases [16]. Potentiostatic routes have been shown to generate Ni-NWs with ellipsoidal grain shapes exhibiting similar hysteresis loops in perpendicular and parallel directions $[19,22]$. In contrast, the galvanostatic electrodeposition of $\mathrm{Ni}$ and $\mathrm{Ni}-\mathrm{W}$ promotes multilayer deposition with a multi-nuclear growth mechanism, thus generating more symmetric grains $[38,39]$. Additionally, no previous reports have been found for which Ni-NWs or Ni-Npillars were electrodeposited by these methods, which could help to support our claims regarding the different grain shapes. Therefore, further morphological characterization, such as a transmission electron microscopy study, is required to determine the $\mathrm{Ni}$ and $\mathrm{NiO}$ phases, as well as the texture of the grains.

Finally, it is worth mentioning that other Ni nanostructures have been used to coat semiconductors, leading to interesting magnetic effects. For instance, carbon nanotubes decorated with Ni nanoparticles have been applied for sensing quantum wave propagations in a variable magnetic field [40]. The advantage of $\mathrm{Ni}$ against carbon allotropes is their adhesive strength on substrates. These values have been reported around 3.5 GPa for Ni-NWs [41] and 714.1 MPa for nanotubes [42]. Therefore, the development of scalable Ni-Npillars seems to be an interesting way to design magnetic networks, which are good candidates for developing magnetic memories, magneto-optical switches, and thermo-optical amplifiers [43,44]. Moreover, considering that Ni-Npillars have a high surface area and tunable aspect ratio, they can be a useful platform for the growth of $\mathrm{NiO}$ on the walls of the pillars to obtain multifunctional metal/oxide devices. This is feasible to undergo, even at room temperature, and was observed in the XRD-spectra of Figure 3. The size of the oxide grain can be controlled in polycrystalline $\mathrm{Ni}$ and is well described by the Mott-Cabrera model for low-temperature oxidation [45]. The oxidation kinetics on a polycrystalline Ni surface occurs by ion transport on the metal phase and mostly happens at the grain boundaries [45]. Since this process is viable in Ni-Npillars, they are good candidates to support $\mathrm{NiO}$ as a nanostructured base for lithium-ion battery anodes [46,47]. The efficiency of the ion exchange is highly affected by the grain size of the $\mathrm{NiO}$ and is crucial to developing these electrodes [48].

\section{Materials and Methods}

\subsection{Fabrication of Porous Alumina Membranes onto Si}

To fabricate PAMs, high purity $\mathrm{Al}(99.995 \%)$ was deposited on polished $n$-type $\mathrm{Si}$ (100) wafers with $1-10 \Omega / \mathrm{cm}$ by electron beam evaporation under high vacuum conditions $\left(\sim 10^{-7}\right.$ Torr base pressure). Afterward, the $\mathrm{Al}$ film with a thickness of $3 \mu \mathrm{m}$ was subjected to a double anodization process, leading to a well-order porous alumina layer, as described in [49]. The pore characteristics can be tuned by adjusting the anodization time and the chemical etching procedure. A pore pattern with a $60 \mathrm{~nm}$ 
diameter was created using an etching process with $5 \mathrm{wt} \%$ of phosphoric acid solution at room temperature for $60 \mathrm{~min}$. This step removes the oxide layer at the bottom of the PAM pores, leaving the Si exposed for the Ni nucleation.

\subsection{Synthesis of Ni Nanopillars}

To study the growth mechanism, Ni-Npillars were synthesized by potentiostatic and galvanostatic electrochemical techniques using the same cell configuration. The deposition procedures were carried out using an electronic analyzer $\mathrm{CHI1140B}$ provided by $\mathrm{CH}$ Instruments (Texas, USA) with a working solution of $\mathrm{NiSO}_{4} \cdot 6 \mathrm{H}_{2} \mathrm{O}\left(0.050 \mathrm{M}\right.$, Sigma-Aldrich, MO, USA), $\mathrm{H}_{3} \mathrm{BO}_{3}(0.040 \mathrm{M}, \mathrm{Merck}, \mathrm{MO}, \mathrm{USA})$, and Saccharin (0.016 M, Sigma-Aldrich), purged with Ar for $10 \mathrm{~min}$. The Si substrates, previously prepared with the PAM mask, were used as a working electrode with an exposed area of $0.4 \mathrm{~cm}^{2}$. Additionally, a stainless steel plate was used as a counter electrode and an Ag/AgCl electrode as a reference. Galvanostatic and potentiostatic electrodepositions were carried out using a current density of $1.875 \mathrm{~mA} / \mathrm{cm}^{2}$ and a potential of $-1.75 \mathrm{~V}$, respectively. Both methods were employed until charges of $1 \mathrm{C}, 2 \mathrm{C}$, and $3 \mathrm{C}$ were reached. After the Ni nanostructures were deposited, the PAM templates were removed with a solution of $\mathrm{NaOH} 1.25 \mathrm{M}$ for $3 \mathrm{~h}$. Finally, the samples were cleaned with MiliQ water to remove any trace of oxide remaining on the Npillars.

\subsection{Characterizations}

The samples were characterized by scanning electron microscopy (SEM) using a LEO model VP1400 (LEO Electron Microscopy Inc., New York, USA). The atomic structure of the Ni-Npillars was performed by X-ray diffraction (XRD), using a diffractometer D8 Advance provided by Bruker (Massachusetts, USA) and equipped with $\mathrm{CuK} \alpha$ radiation source (1.56 ̊). Additionally, a custom-built alternating force gradient magnetometer (AGM) was used at room temperature to study the anisotropic magnetic properties. Two distinguished propagation directions of the magnetic field were considered: parallel $(\|)$ and perpendicular $(\perp)$ to the long axis of the Npillars.

\section{Conclusions}

Within this work, galvanostatic and potentiostatic techniques have been used to successfully grow Ni-Npillars onto Si substrate using a PAM as a template. The periodic pore distribution of the AAO is crucial to obtain Npillars with a high aspect ratio to create an efficient magnetic nanosystem. The electrodeposition technique and the charge level define the mean height distribution of the Ni-Npillars. The XRD confirmed that the grain size of the polycrystalline structures is bigger in the galvanostatic samples. The magnetic properties show a strong dependence on the growing electrochemical method and the mean height of all samples. Npillar arrays with similar heights but fabricated by different electrodeposited techniques exhibit different magnetization hysteresis in the perpendicular direction. Differences related to the electrodeposition method led to the formation of unique $\mathrm{Ni}$ nanostructures with remarkable vectorial magnetization dependence, which can be considered for the development of multimode systems.

Author Contributions: Conceptualization, M.B. and P.C.; methodology, B.D. and P.H.; validation, A.R.; formal analysis, J.C.D.; writing-review and editing, J.A.G.-M.; supervision, R.d.R. and S.A.H.; funding acquisition, S.A.H. All authors have read and agreed to the published version of the manuscript.

Funding: This research was funded by the Air Force Office of Scientific Research, grant number FA9550-18-1-0438, Fondecyt grant \#1201589 and Fondecyt postdoctoral grant \#3190552, and Fondequip projects EQM150101 and also by the support of MINECON-Chile through project Millennium Nucleus MULTIMAT-ICM/MINECON.

Conflicts of Interest: The authors declare no conflict of interest. The funders had no role in the design of the study; in the collection, analyses, or interpretation of data; in the writing of the manuscript; or in the decision to publish the results. 


\section{References}

1. Izyumskaya, N.; Tahira, A.; Ibupoto, Z.H.; Lewinski, N.; Avrutin, V.; Özgür, Ü.; Topsakal, E.; Willander, M.; Morkoç, H. Review-Electrochemical biosensors based on ZnO. ECS J. Solid State Sci. Technol. 2017, 6, 84-100.

2. Schopphoven, C.; Tschöpe, A. Magnetic anisotropy of nickel nanorods and the mechanical torque in an elastic environment. J. Phys. D Appl. Phys. 2018, 51, 115005. [CrossRef]

3. Wang, Z.; Chen, F.; Kannan, P.; Ji, S.; Wang, H. Nickel phosphate nanowires directly grown on Ni foam as binder-free electrode for pseudocapacitors. Mater. Lett. 2019, 257, 126742.

4. Zhang, J.; Xiang, W.; Liu, Y.; Hu, M.; Zhao, K. Synthesis of high-aspect-ratio nickel nanowires by dropping method. Nanoscale Res. Lett. 2016, 11, 118. [PubMed]

5. Hamidi, S.M.; Sobhani, A.; Aftabi, A.; Najafi, M. Optical and magneto-optical properties of aligned Ni nanowires embedded in polydimethylsiloxane. J. Magn. Magn. Mater. 2015, 374, 139-143.

6. Nasirpouri, F.; Peighambari-Sattari, S.M.; Bran, C.; Palmero, E.M.; Eguiarte, E.B.; Marquez, M.; Patsopoulos, A.; Kechrakos, D. Geometrically designed domain wall trap in tri-segmented nickel magnetic nanowires for spintronics devices. Sci Rep. 2019, 9, 9010.

7. Cheng, H.E.; Lin, S.Y.; Tian, D.C. Fabrication of nickel nanopillar-array electrodes for water electrolysis. J. Electrochem. Soc. 2014, 161, E202-E206.

8. Lee, J.K.; Shin, J.H.; Lee, H.; Yoon, W.Y. Characterization of nano silicon on nanopillar-patterned nickel substrate for lithium ion batteries. J. Electrochem. Soc. 2014, 161, A1480-A1485.

9. Wang, S.; Chen, K.; Wang, M.; Li, H.; Chen, G.; Liu, J.; Xu, L.; Jian, Y.; Meng, C.; Zheng, X.; et al. Controllable synthesis of nickel nanowires and its application in high sensitivity, stretchable strain sensor for body motion sensing. J. Mater. Chem. C. 2018, 6, 4737-4745.

10. Guiliani, J.; Cadena, J.; Monton, C. Template-assisted electrodeposition of Ni and Ni/Au nanowires on planar and curved substrates. Nanotechnology 2018, 29, 075301. [CrossRef]

11. Lee, J.D.; Kim, H.S.; Jeong, S.Y.; Kim, K.H.; Lee, J.J.; Kim, J.E. Magnetic characteristics of thin Ni films electrodeposited on n-Si(1 1 1). Curr. Appl. Phys. 2010, 10, 249-254.

12. Sofiah, A.G.N.; Kananathan, J.; Samykano, M.; Ulakanathan, S.; Lah, N.A.C.; Harun, W.S.W.; Sudhakar, K.; Kadirgama, K.; Ngui, W.K.; Siregar, J.P. Electrochemical deposited nickel nanowires: Influence of deposition bath temperature on the morphology and physical properties. IOP Conf. Ser.-Mater. Sci. Eng. 2017, 257, 012032. [CrossRef]

13. Proenca, M.P.; Sousa, C.T.; Ventura, J.; Vazquez, M.; Araujo, J.P. Ni growth inside ordered arrays of alumina nanopores: Enhancing the deposition rate. Electrochim. Acta 2012, 72, 215-221. [CrossRef]

14. Banerjee, A.; Halder, N. Electrochemical growth of ordered nickel nano-rods within a composite structure of anodic-alumina-membrane/metal/silicon substrate. J. Nanosci. Nanotechnol. 2010, 10, 4252-4258. [CrossRef] [PubMed]

15. Joo, S.W.; Banerjee, A.N. FESEM studies of densely packed aligned nickel nanopillars on silicon substrate by electrochemical deposition through porous alumina membrane. Mater. Sci. Eng. B. 2010, 175, 36-40. [CrossRef]

16. Cassoux, P.; Valade, L.; Fabre, P.L. Electrochemical methods, electrocrystallization. In Comprehensive Coordination Chemistry II; McCleverty, J.A., Meyer, T.J., Eds.; Elsevier Ltd.: Amsterdam, The Netherland, 2003; pp. 761-773.

17. Shi, J.B.; Chen, Y.C.; Lee, C.W.; Lin, Y.T.; Wu, C.; Chen, C.J. Optical and magnetic properties of 30 and $60 \mathrm{~nm}$ Ni nanowires. Mater. Lett. 2008, 62, 15-18. [CrossRef]

18. Rahman, I.Z.; Razeeb, K.M.; Rahman, M.A.; Kamruzzaman, M. Fabrication and characterization of nickel nanowires depositedon metal substrate. J. Magn. Magn. Mater. 2003, 262, 166-169.

19. Fuentes, G.P.; Holanda, J.; Guerra, Y.; Silva, D.B.O.; Farias, B.V.M.; Padrón-Hernández, E. Micromagnetic simulation and the angular dependence of coercivity and remanence for array of polycrystalline nickel nanowires. J. Magn. Magn. Mater. 2017, 423, 262-266. [CrossRef]

20. Evans, P.; Hendren, W.R.; Atkinson, R.; Wurtz, G.A.; Dickson, W.; Zayats, A.V.; Pollard, R.J. Growth and properties of gold and nickel nanorods in thin film alumina. Nanotechnology 2006, 17, 5749-5753. [CrossRef]

21. Oh, S.L.; Kim, Y.R.; Malkinski, L.; Vovk, A.; Whittenburg, S.L.; Kim, E.M.; Jung, J.S. Magnetic properties of nickel nanostructures grown in AAO membrane. J. Magn. Magn. Mater. 2007, 310, e827-e829. [CrossRef] 
22. Kartopu, G.; Yalçın, O.; Choy, K.L.; Topkaya, R.; Kazan, S.; Aktaş, B. Size effects and origin of easy-axis in nickel nanowire arrays. J. Appl. Phys. 2011, 109, 033909. [CrossRef]

23. Ren, Y.; Zhang, S.; Zhang, L.; He, X. 3D Si@Cu-Ni nano-pillars array composite as carbon/binder free anode for lithium ion battery. J. Matter Res. Technol. 2020, 9, 1549-1558. [CrossRef]

24. Kang, L.; Zhang, S.; Lin, R. Preparation of tin nano-spheres film anode based on copper-nickel nano-pillars for lithium ion batteries. Adv. Mater. Res. 2012, 399, 1467-1472. [CrossRef]

25. Batail, P. Electrochemical crystal growth. In Encyclopedia of Materials: Science and Technology, 2nd ed.; Jürgen-Buschow, K.H., Cahn, R.W., Flemings, M.C., Ilschner, B., Kramer, E.J., Mahajan, S., Veyssiere, P., Eds.; Elsevier Ltd.: Nantes, France, 2001; pp. 2518-2520.

26. Lambers, E.S.; Dykstal, C.N.; Seo, J.M.; Rowe, J.E.; Holloway, P.H. Room-temerature oxidation of Ni(110) at low and atmospheric oxygen pressures. Oxid. Met. 1996, 45, 301-321. [CrossRef]

27. Mateos, D.; Valdez, B.; Castillo, J.R.; Nedev, N.; Cueriel, M.; Perez, O.; Arias, A.; Tiznado, H. Synthesis of high purity nickel oxide by a modified sol-gel method. Ceram. Int. 2019, 45, 11403-11407. [CrossRef]

28. Liu, C.; Li, C.; Ahmed, K.; Mutlu, Z.; Ozkan, C.S.; Ozkan, M. Template free and binderless NiO nanowire foam for Li-ion battery anodes with long cycle life and ultrahigh rate capability. Sci. Rep. 2016, 6, 29183. [CrossRef]

29. Richardson, J.T.; Scates, R.; Twigg, M.V. X-ray diffraction study of nickel oxide reduction by hydrogen. Appl. Catal. A. 2003, 246, 137-150. [CrossRef]

30. Santos, A.; Vojkuvka, L.; Pallarés, J.; Ferré-Borrull, J.; Marsal, L.F. Cobalt and nickel nanopillars on aluminium substrates by direct current electrodeposition process. Nanoscale Res. Lett. 2009, 4, 1021-1028. [CrossRef]

31. Qin, J.; Nogués, J.; Mikhaylova, M.; Roig, A.; Muñoz, J.S.; Muhammed, M. Differences in the magnetic properties of $\mathrm{Co}, \mathrm{Fe}$, and $\mathrm{Ni}$ 250-300 nm wide nanowires electrodeposited in amorphous anodized alumina templates. Chem. Mater. 2005, 17, 1829-1834. [CrossRef]

32. Chandra, S.; Kumar, A.; Kumar-Tomar, P. Synthesis of Ni nanoparticles and their characterizations. J. Saudi Chem. Soc. 2014, 18, 437-442. [CrossRef]

33. Guerra, Y.; Peña-Garcia, R.; Padrón-Hernández, E. Magnetic reversion in real nickel and cobalt nanowires and the angulardependence of coercivity. J. Magn. Magn. Mater. 2018, 452, 17-22. [CrossRef]

34. Samardak, A.S.; Sukovatitsina, E.V.; Ognev, A.V.; Chebotkevich, L.A.; Mahmoodi, R.; Hosseini, M.G.; Peighambari, S.M.; Nasirpouri, F. Geometry dependent magnetic properties of Ni nanowires embedded in self-assembled arrays. Physcs. Proc. 2011, 22, 549-556. [CrossRef]

35. Luo, Y.; Zhang, J.C.; Shen, Y.; Jiang, S.T.; Liu, G.Y.; Wang, L.J. Preparation and magnetic properties of nickel nanorods by thermal decomposition reducing methods. Trans. Nonferrous Met. Soc. China. 2006, 16, s96-s100. [CrossRef]

36. Meneses, F.; Urret, S.E.; Escrig, J.; Bercoff, P.G. Temperature dependence of the effective anisotropy in Ni nanowire arrays. Curr. Appl. Phys. 2018, 18, 1240-1247. [CrossRef]

37. Moreno, R.; Poyser, S.; Meilak, D.; Meo, A.; Jenkins, S.; Lazarov, V.K.; Vallejo-Fernandez, G.; Majetich, S.; Evans, R.L. The role of faceting and elongation on the magnetic anisotropy of magnetite $\mathrm{Fe}_{3} \mathrm{O}_{4}$ nanocrystals. Sci. Rep. 2020, 10, 2722. [CrossRef] [PubMed]

38. Rashidi, A.M. A galvanostatic modeling for preparation of electrodeposited nanocrystalline coatings by control of current density. J. Mater. Sci. Technol. 2012, 28, 1071-1076. [CrossRef]

39. Quiroga-Arganaraz, M.P.; Ribotta, S.B.; Folquer, M.E.; Zelaya, E.; Llorente, C.; Ramallo-López, J.M.; Benítez, G.; Rubert, A.; Gassa, L.M.; Vela, M.E.; et al. The chemistry and structure of nickel-tungsten coatings obtained by pulse galvanostatic electrodeposition. Electrochim. Acta 2012, 72, 87-93. [CrossRef]

40. García-Merino, J.A.; Jímenez-Marín, E.; Mercado-Zúñiga, C.; Trejo-Valdez, M.; Vargas-García, J.; Torres-Torres, C. Quantum and bistable magneto-conductive signatures in multiwall carbon nanotubes decorated with bimetallic Ni and Pt nanoparticles driven by phonons. OSA Continuum. 2019, 2, 1285-1295. [CrossRef]

41. Celik, E.; Guven, I.; Madenci, E. Mechanical characterization of nickel nanowires by using a customized atomic force microscope. Nanotechnology 2011, 22, 155702. [CrossRef]

42. Il'ina, M.V.; Il'in, O.I.; Smirnov, V.A.; Blinov, Y.F.; Konoplev, B.G.; Ageev, O.A. Scanning probe techniques for characterization of vertically aligned carbon nanotubes. In Atomic-force Microscopy and Its Applications; Tański, T., Staszuk, M., Ziębowicz, B., Eds.; IntechOpen: London, UK, 2018; pp. 49-68. 
43. Bentley, A.K.; Ellis, A.B.; Lisensky, G.C.; Crone, W.C. Suspensions of nickel nanowires as magneto-optical switches. Nanotechnology 2005, 16, 10. [CrossRef]

44. Zhang, Y.; Xu, W.; Xu, S.; Fei, G.; Xiao, Y.; Hu, J. Optical properties of $\mathrm{Ni}$ and $\mathrm{Cu}$ nanowire arrays and Ni/Cu superlattice nanowire arrays. Nanoscale Res. Lett. 2012, 7, 569. [CrossRef] [PubMed]

45. Payne, B.P.; Grosvenor, A.P.; Biesinger, M.C.; Kobe, B.A.; Stewart-McIntyre, N. Structure and growth of oxides on polycrystalline nickel surfaces. Surf. Interface Anal. 2007, 39, 582-592. [CrossRef]

46. Khalil, A.; Lalia, B.S.; Hashaikeh, R. Nickel oxide nanocrystals as a lithium-ion battery anode: Structure-performance relationship. J. Mater. Sci. 2016, 51, 6624-6638. [CrossRef]

47. Kim, J.; Kang, H.; Hwang, K.; Yoon, S. Thermal decomposition study on $\mathrm{Li}_{2} \mathrm{O}_{2}$ for $\mathrm{Li}_{2} \mathrm{NiO}_{2}$ synthesis as a sacrificing positive additive of lithium-ion batteries. Molecules 2019, 24, 4624. [CrossRef]

48. Cheng, M.; Ye, Y.; Chiu, T.; Pan, C.; Hwang, B. Size effect of nickel oxide for lithium ion battery anode. J. Power Sources 2014, 253, 27-34. [CrossRef]

49. Hevia, S.A.; Homm, P.; Guzmán, F.; Ruiz, H.M.; Muñoz, G.; Caballero, L.S.; Favre, M.; Flores, M. Pulsed laser deposition of carbon nanodot arrays using porous alumina membranes as a mask. Surf. Coat. Technol. 2014, 253, 161-165. [CrossRef]

Sample Availability: Not available.

Publisher's Note: MDPI stays neutral with regard to jurisdictional claims in published maps and institutional affiliations.

(C) 2020 by the authors. Licensee MDPI, Basel, Switzerland. This article is an open access article distributed under the terms and conditions of the Creative Commons Attribution (CC BY) license (http://creativecommons.org/licenses/by/4.0/). 